\title{
Ceramics Research in Canada
}

Though Canada's ceramics industry is mainly based in the traditional areas of glass, whitewares, clay, and refractories, interest in advanced ceramics is increasing. Major programs can be found in universities, government, and industry; and the Canadian University-Industry Council on Advanced Ceramics (CUICAC) has been established to promote the development of these materials. Five major universities and about 30 private companies participate in CUICAC. Several other universities plan to join this year.

\begin{tabular}{cc}
\hline \multicolumn{2}{c}{ CUICAC Universities } \\
Queen's University & $\begin{array}{c}\text { Kingston, } \\
\text { Ontario } \\
\text { Hamilton, } \\
\text { Ontario } \\
\text { McMaster University }\end{array}$ \\
$\begin{array}{c}\text { Vancouver, } \\
\text { University of } \\
\text { British Columbia } \\
\text { Columbia }\end{array}$ \\
Ecole Polytechnique & $\begin{array}{c}\text { Montreal, } \\
\text { Quebec }\end{array}$ \\
Technical University & Halifax, \\
of Nova Scotia & Nova \\
& Scotia \\
& \\
\hline
\end{tabular}

\section{Focusing on Electronic Materials}

Work in ceramics at Queen's University is centered in the Department of Physics, Applied Solid State Group. It focuses on electronic materials, including transition metal glasses $\left(\mathrm{V}_{2} \mathrm{O}_{5}: \mathrm{P}_{2} \mathrm{O}_{5}\right)$, semiconducting or metallic oxides $\left(\mathrm{VO}_{2}\right.$ or $\left.\mathrm{LaCrO}_{3}\right)$, and fast-ion conductors based on $\mathrm{Na}, \mathrm{F}^{-}$, and $\mathrm{Ag}^{+}$compounds.

Other research groups at Queen's are involved in analysis. One group uses an accelerator-based method for detecting trace elements of the transition metal series and Rutherford backscattering for detecting surface layers. Ultrasonics work involves transducer design and tomography for looking at internal structures. A laserbased interferometer system is used for noncontact ultrasonics.

Interest in $\mathrm{LaCrO}_{3}$ or $\mathrm{LaNiO}_{4}$ is based on their high conductivities, especially at high temperatures, and their potential use for high temperature fuel cell electrodes. The conducting mechanism of some of these materials has been determined by temperature and pressure studies. $\mathrm{LaCrO}_{3}$ is stable in air up to $1400^{\circ} \mathrm{C}$ and has electrochemical catalytic activity; it is being considered as an electrode in combination with porous zirconia heating elements for high temperature furnaces.

Queen's University has joint projects with McMaster University and with Almax
Industries Ltd. The joint project with McMaster University includes work on sodium/hydrogen beta alumina. Hydronium beta/beta prime aluminas have been fabricated by ion exchange of $\mathrm{Na} / \mathrm{K}$ alumina for steam electrolysis and fuel cells operating at $300^{\circ} \mathrm{C}$. The collaboration with Almax has created materials and testing techniques for the production of lead zirconate titanate (PZT) ceramics. (These materials are being developed for ultrasonic transducers.) Another project with Almax involves the design of an alkali metal thermoelectric generator using a ceramic Naconducting membrane.

Other work in piezoelectrics at Queen's has included fabrication of highly oriented PZT thin films using radio-frequency and direct-current planar magnetron sputtering. The films are being used for surface acoustic wave substrates, high frequency bulk wave transducers, and electro-optic devices. Reactive sputtering of metal targets under high oxygen partial pressure is being developed as a method for fabricating complex oxides. Other thin film technologies, and thermal and electron beam evaporation, are being used to produce high efficiency electroluminescent display panels based on ZnS.

\section{Coatings for Conduction and Erosion Resistance}

Ceramics research at the Technical University of Nova Scotia takes place in the Department of Engineering Physics. Interest focuses on perovskites, which have resistivities of $10^{-4}$ to $10^{8} \Omega \mathrm{cm}$, making them useful for magnetohydrodynamic devices, fuel cells, and electrolysis applications. The selective substitution and mixing of different perovskite phases can be used to achieve chemically compatible ceramics for application as insulators, resistors or conductors in microcircuitry, and as high current electrodes for use at high temperatures and under severe oxidizing conditions.

These perovskites have been successfully plasma-sprayed onto expanded nickel grids to form electrocatalysts. Coarse particles of $\mathrm{Ni}-\mathrm{Cr}$ form a preliminary bond coat with the fine electrocatalyst particles deposited on these larger particles. There was no significant loss of electrocatalytic properties or mechanical degradation after 100 hours under simulated operating conditions. Long-term tests in progress are using commercial electrolyzer equipment for such application as the electrolysis of alkaline solutions.

Continued

\section{Research in Canadian Universities}

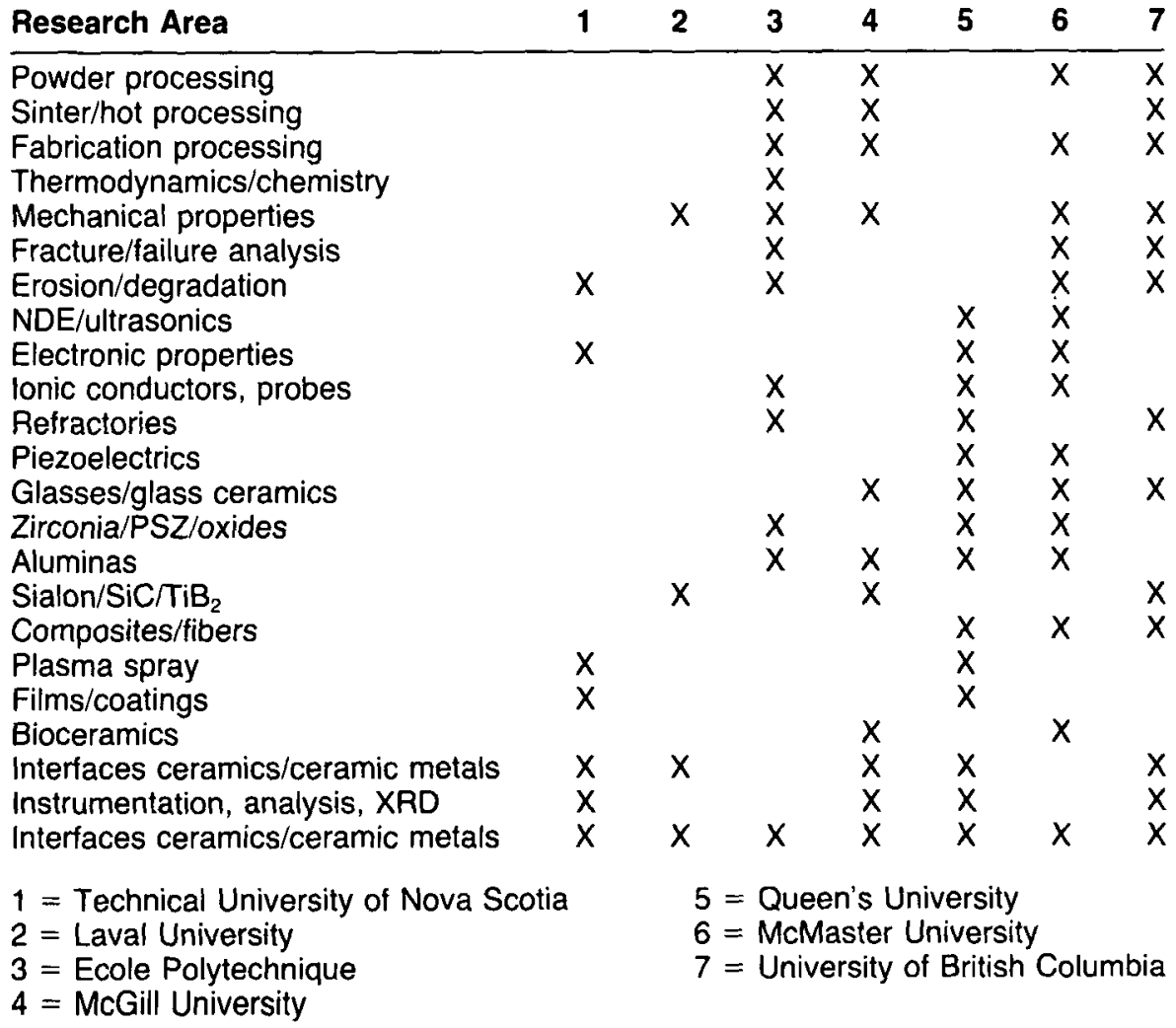

Source: Canadian Ceramics Quarterly, February 1986. 
Plasma spraying is also being used to apply erosion-resistant coatings. Currently under investigation is the problem of thermal expansion mismatch between the substrate and the coating. A mixed coating composed of a highly erosion resistant ceramic and a second ceramic with higher thermal expansion is deposited. Mixtures composed of $\mathrm{Al}_{2} \mathrm{O}_{3}$ and $\mathrm{La}_{2} \mathrm{NiO}_{4}$ have thermal expansion coefficients close to those of carbon steels used for coal combustion components and have adequate erosion resistance. After preliminary tests, the coating mixtures will be tested in situ in coal-fired generating stations. Ceramic coatings and bulk ceramic inserts are also under development for combustor nozzles.

\section{Metal-Ceramic Bonding and More}

At the University of British Columbia ceramics research is divided into two areas refractories and general ceramics. Refractories research is concentrated on composite refractories, slag-resistant refractories, and the thermal shock of refractories. In composite refractories, porosity-gradient bricks are being made by vertical or horizontal zoning during pressing. Using such a concept, a brick can be designed for a desired temperature drop from a predetermined hot-face temperature. These bricks can be used to line furnace walls for a wide range of applications.

Ceramics research projects involve processing of $\mathrm{SiC}, \mathrm{Si}_{3} \mathrm{~N}_{4}$ and metal-ceramic composites and interfaces. The University of British Columbia has developed a model to predict the sessile drop behavior of a molten metal on an oxide surface, provided the reaction at the interface is not extensive. (Other stipulations require that the metal in its oxidative state must form a spinel-like compound whose free energy of formation is known or can be estimated.) The model agrees well with experimental data and is being extended to predict the sessile drop behavior of sapphire-alloy systems as well as $\mathrm{Si}_{3} \mathrm{~N}_{4}$ and metals/alloys under varying nitrogen pressures.

The University of British Columbia is also considering plasma synthesis of $\mathrm{SiC}$ powders and has built a dc arc plasma unit. Ultrafine, uniform, spherical powders of $\mathrm{SiC}(50-75 \mathrm{~nm})$ have been produced. Plans are to extend the work to $\mathrm{Si}_{3} \mathrm{~N}_{4}$. Other current and planned research includes: $r f$ plasma synthesis of $\mathrm{SiC}$ and $\mathrm{Si}_{3} \mathrm{~N}_{4}$; hotpressing and sintering of $\mathrm{SiC}$; cold and hot isostatic pressing of $\mathrm{SiC}$ and $\mathrm{Si}_{3} \mathrm{~N}_{4}$; and component fabrication (slip casting, injection molding, cold pressing) and testing.

\section{More Fuel Cell and Ultrasonics \\ Research}

McMaster University, the only university in Canada that offers an undergraduate degree in ceramics engineering, has several ceramics projects in its Department of Materials Science and Engineering.
Areas of interest include synthesis of powders, shaping and sintering, and nondestructive evaluation using ultrasonics for flaw detection.

Beta-alumina is receiving much attention especially as a super-ionic electrolyte. As already described, hydronium beta/beta prime alumina is being evaluated for use in hydrogen-oxygen fuel cells and steam electrolysis. For operation at $300^{\circ} \mathrm{C}$, high pressure steam is required to achieve maximum efficiency because at one atmosphere the electrolyte partly dehydrates.

Beta-alumina can also deflect cracks at high temperatures, when combined with partly stabilized zirconia (PSZ). Cracks are attracted to beta-alumina particles by their lower elastic modulus. A PSZ containing $120 \mu \mathrm{m}$ beta-alumina particles acts in a pseudoplastic way, indicating it has a tougher response to applied stress. In fact, this material has an initial Weibull modulus (probability of failure vs. the failure stress) of 43 and has the same deflection behavior at high temperatures. Further work is under way to increase the fracture strength while maintaining the high value of modulus.

Similar research involves strengthening bioglass and glass-ceramics. Bioglass was found to be far more sensitive to static fatigue than conventional soda-lime-silica glass. Because strength can be drastically reduced by subsurface and surface flaws, a large program is looking at identifying these flaws nondestructively.

In McMaster's experiments, the general shape of artificially introduced flaws can be detected ultrasonically. Time domain data is converted to a frequency spectrum in which the central frequency and full-width at half maximum of the largest spectral peak can be derived. The observed variation of these parameters with flaw size agrees well with theoretical models.

\section{Characterization of Ceramics}

Ecole Polytechnique has four programs on advanced ceramics in the metallurgical department at the University of Montreal. Seven faculty members are involved in the following projects: (1) characterization of thermochemical and thermomechanical properties; (2) ceramic electrolytes for probes (chemical detection); (3) wear of bioceramics; and (4) composition and structural analysis of materials, including characterization and fabrication of plasmasprayed $\mathrm{SiC}$ coatings and alumina-SiC composites.

Most of the research is devoted to ceramic probes for detecting various elements. Several projects focus on beta alumina, particularly for use in metallurgical industries for detecting phosphorous, sulfur, and other elements. A Na and $\mathrm{Li}$ detector based on beta-alumina is being developed for aluminum melting processes; another probe for detecting arsenic is in- tended for pyrometallurgical processes. In addition to ion-substituted beta-alumina for probes, an oxygen detector mini-probe based on $\mathrm{ZrO}_{2}$ is being developed.

Several other projects involve $\mathrm{MgO}$ partly stabilized zirconia (PSZ). Again, applications are for metallurgical industries, including continuous casting nozzles for steel, and inserts for ladle slide-gates. Ecole Polytechnique has had some success improving the toughness of these materials and predicts the availability of materials with fracture toughness of about $40 \mathrm{MPa}$ $\mathrm{m}^{1 / 2}$, rupture stress of $500 \mathrm{MPa}$ at $1400^{\circ} \mathrm{C}$, and Weibull modulus above 20. To assist these and other projects, a major facility the Laboratory for Characterization and Microscopy of Materials - is available for microstructural characterization. Capabilities in SEM, STEM, image analysis, Auger spectroscopy, and $x$-ray diffraction are available.

\section{Other University Research}

Several other universities that are not members of CUICAC are doing work in ceramics. For example, Laval University is investigating hot pressing and hot isostatic pressing of boron carbide and silicon borides. McGill University is interested in medical prostheses and heat engines, and specifically in joining $\mathrm{SiC}$ to heat-resistant alloys, sialons, sintering behavior in reactive aluminas, and calcium phosphates. Other research at McGill involves powder preparation and characterization, slip casting, extrusion, and injection molding.

\section{Industrial Research at AECL}

Atomic Energy of Canada Limited (AECL), a founding industrial member of CUICAC, is involved in commercial development of advanced ceramics for nuclear and non-nuclear applications. Such development is carried out by AECL's Research Company, which operates two laboratories, Chalk River and Whiteshell.

AECL established the Canadian nuclear ceramics industry by developing powder and pellet processing technology and transferring it to Canadian companies. Included were the development of nuclear fuel and ceramic pressure tubes. Current programs involve nuclear ceramics, nuclear waste immobilization, nuclear waste encapsulation, fusion ceramics, and commercial/industrial ceramics.

AECL has developed processes for producing nuclear fuels based on thoria. Solgel technology is used to make both high-density ceramic spheres and powders for fabricating pellets. Work is now focused on developing microstructures that would allow urania-based fuels to be used at higher powers for longer times. In addition, researchers are looking at uraniabased materials that are doped with stable elements to simulate the composition and

Continued 
Research at Canadian Laboratories

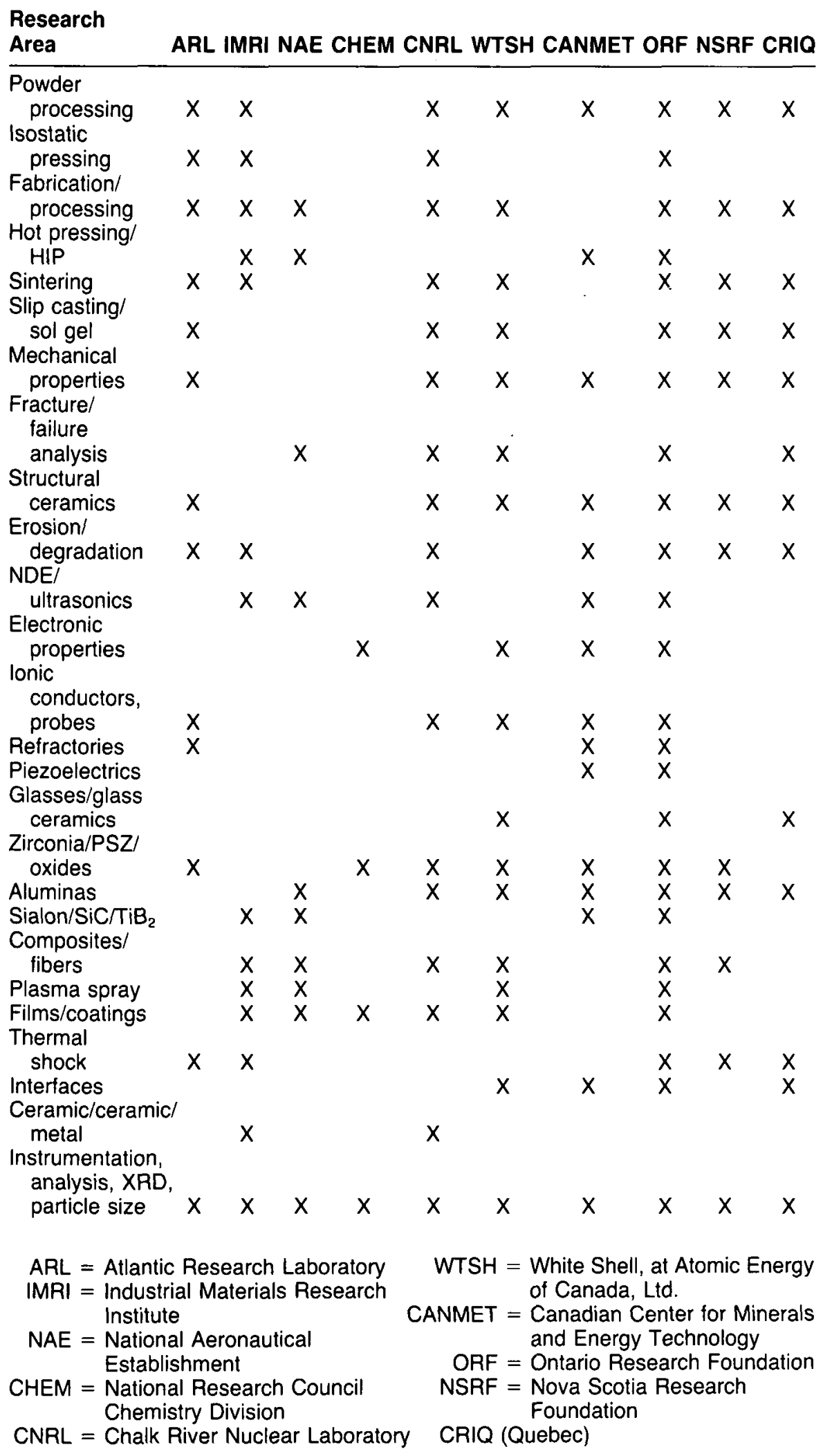

Source: Canadian Ceramics Quarterly, August 1986. phase-microstructure of high-burnup nuclear fuel.

For nuclear waste immobilization, AECL is developing highly insoluble matrices of glass or ceramics that would incorporate or immobilize radioactive fission product wastes. Pilot-scale equipment has converted the liquid waste into a calcined powder, which is mixed with glass, then melted and stored in stainless steel cans. Continuous gel and slurry-based processes have also been developed for converting liquid waste into calcined powders. The powders are then incorporated into borosilicate, alumina-silicate, spheneglass, and SYNROC waste forms.

Sphene glass-ceramics, pioneered at AECL's Whiteshell laboratory, consist of discrete $\mathrm{CaTiSiO}_{5}$ crystals in a matrix of alumino-silicate glass, which results in improved chemical resistance and mechanical strength. Both traditional and sol-gel processes are being used. Another program is looking at optimizing the formulation of SYNROC B and substituting pressureless sintering for hot pressing in order to streamline production.

Lithium-based ceramics are being investigated for application as a fusion breeder blanket. This blanket would surround the plasma in an operating fusion reactor and host a reaction between fusion neutrons and lithium to produce tritium gas for fuel. The blanket would also provide a source of heat to generate electricity.

The major objective of this fusion program is to optimize microstructures for the production and removal of tritium gas under irradiation. Heavy emphasis is placed on fabrication technology, including solgel routes for making high-purity lithium aluminate powder. Both conventional and alkoxide precursers will be evaluated.

In addition to nuclear uses, AECL proposes to apply advanced ceramics technology to commercial/industrial uses. The wide range of possible applications includes wear-resistant coatings, sensors, mechanical seals, sodium heat engines, ceramic journals and bearings, and pressure tubes. Specific projects involve the preparation of stabilized zirconia powders, using thoria for high-purity crucibles, ceramic composites reinforced with metal precipitates, microporous ceramics, colloidal ferrites, "flexible" ceramic coatings, and ion-conducting ceramics.

The Chalk River laboratory has a comprehensive capability for nondestructive evaluation. Programs are focused on neutron diffraction, tomography, ultrasonics, eddy current testing, gamma and neutron radiography, and $x$-ray diffraction.

Neutron diffraction is attractive because it can provide information on a component's subsurface or bulk volume. Access to transmitted beams also aids in determin- 


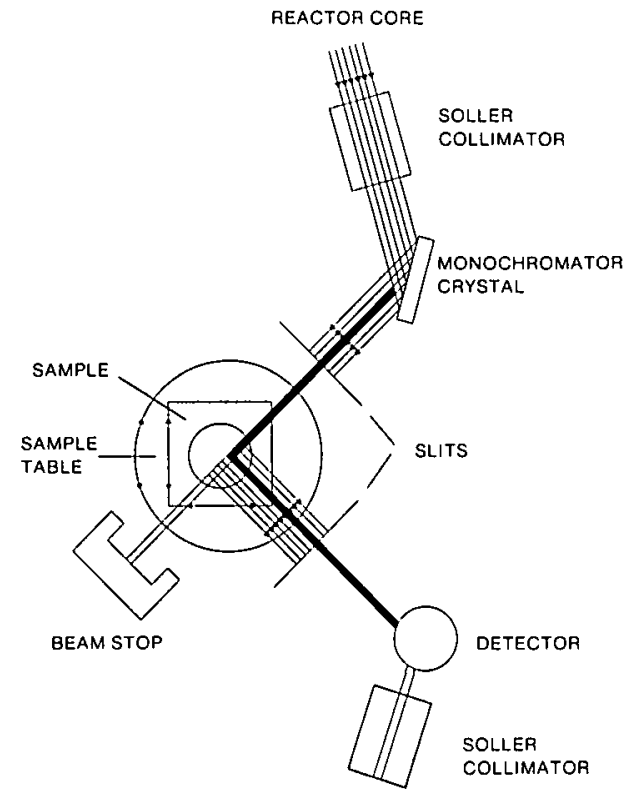

Schematic of Chalk River's residual strain measurement using slits to define a small beam. After a beam of polychromatic neutrons is extracted from the reactor core, a monochromatic beam is obtained. The slits define a narrow beam which usually passes through the sample and reaches the beam stop. A slit is placed in the diffracted beam from which all the diffracted information originates. (From Ref. 2, Nov. 1986.)

ing the complete residual strain tensor. Other advantages are that no surface preparation is needed and that measurements can be made in situ because the neutron beam can pass through container walls. Besides residual strain and strain gradient measurements, neutron diffraction can measure crystallographic texture and texture gradients, the presence and distribution of minority phases, and temperature. Chalk River is using a triple-axis spectrometer for measuring these parameters in a variety of components; including stainless steel pipe, welded $\mathrm{Zr}$-alloy pipe, Ti-alloy forgings, and $\mathrm{Al}_{2} \mathrm{O}_{3}$.

Chalk River is also interested in gammaray computer tomography $(\mathrm{CT})$, especially for ceramics. The technique yields distortion-free images in their correct spatial configuration, and potentially has much higher sensitivity than conventional radiography. CT can be applied to ceramics in both the green and fired state. Because no commercial scanners are available for this type of application, Chalk River developed two prototype scanners that are available for service inspections. These scanners have been used to identify density variations in sintered alumina. Chalk River plans to design an inexpensive scanner specifically for ceramics and is requesting industry input to determine the specifications.

\section{Government Research in Ceramics}

Canada's government laboratories are conducting significant research in ceramics. (AECL, described above, is a federal Crown Corporation accountable to the Minister of Energy, Mines and Resources). The Canadian National Research Council (NRC) has a variety of projects located throughout its laboratories. A coordinated effort in ceramic basic research is the core program. At the Atlantic Research Laboratory (Halifax, Nova Scotia), monolithic components are being developed for medium speed diesel engines, chemical plant components, and oxygen sensors. Processing techniques include slip casting (molding, chemistry of slip preparation) and cold isostatic pressing.

The NRC's Division of Mechanical Engineering at Halifax is directing its efforts toward improving fuel tolerance and thermodynamic efficiency in diesel engines. The materials being studied include silicon nitride, silicon carbide, partly stabilized zirconia, and alumina. Another interest is bearings technology, specifically tribology of ceramics.

The Industrial Materials Research Institute (IMRI) in Boucherville, Quebec is doing work in plasma spraying. Materials include borides, carbides, boride-based cermets, WC-Co composites, and PZT. Applications include screening rolls, graphite electrodes, orthopedic prostheses, and semiconductors. IMRI also is looking at piezoelectric ceramic/polymer composites.

IMRI has developed a process for producing $\mathrm{TiB}_{2}-\mathrm{Fe}$ coatings, based on an in situ exothermic reaction. Agglomerates con taining the reactants (ferrotitanium and boron) are injected through a plasma flame onto the substrate. The coatings have structure similar to rapidly solidified materials, with a fine dispersion of $\mathrm{TiB}_{2}$ (crystalline size less than $1 \mu \mathrm{m}$ ) in an Fe matrix. Hence, agglutination coatings at the particle level are produced as the core particles are coated with another powder. For instance, $\mathrm{SiC}$ could be coated with Al using this process to form a composite coating.

The National Aeronautical Laboratory (Ottawa, Ontario) is also considering coatings for aero-engineer gas path components. For cold sections, chemical vapor-deposited TiN, physical vapordeposited $\mathrm{TiN}$, and ion vapor-deposited $\mathrm{Al}$ are being developed. For hot sections, $\mathrm{Y}_{2} \mathrm{O}_{3}-\mathrm{ZrO}_{2}$ coatings are being developed, specifically for turbine vanes and blades. Facilities include a HIP unit $\left(2000^{\circ} \mathrm{C}, 30,000\right.$ psi, $10.5 \mathrm{in}$. long by $5.5 \mathrm{in}$. diameter working zone), burner rig testing, and high temperature fracture mechanics capability.

The Canada Center for Minerals and Energy Technology (CANMET) in Ottawa, Ontario, is the research arm of the Department of Energy, Mines, and Resources. CANMET is more interested in functional ceramics because the present market ratio favors them (4:1) over structural ceramics. Hence, CANMET is developing materials for use in energy and storage management systems. These include devices based on oxygen-, sodium-, and hydrogenconducting materials for thermoelectric generators, sodium-sulfur batteries, and fuel cells.

Clearly, Canada's ceramic research covers the major areas. With CUICAC's help, more collaborative efforts in advanced ceramics will move Canada toward international recognition in advanced ceramics, building on an international reputation already achieved in zirconia, glasses, proton conductors, and refractories. With additional government assistance, Canadian research facilities will become key players in the development and commercialization of advanced ceramics.

LEONORA S. MILLBERG

\section{References}

1. Canadian Ceramics Quarterly, February, May, and August 1986

2. Transactions of the Canadian UniversityIndustry Council of Advanced Ceramics, June and November 1986.

In The Next Issue:

Accreditation in

Materials Education

Multidisciplinary

Graduate Programs in

Materials

Specific Materials

Science and

Engineering Education

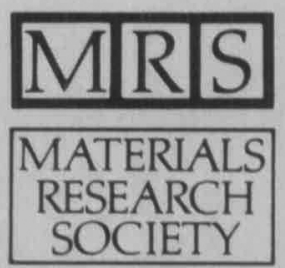

